\title{
A comparative study of the morphology of mammalian true chordae tendineae of the atrioventricular valves
}

\author{
HUTCHISON, J. and REA, P.*
}

\begin{abstract}
Laboratory of Human Anatomy, Thomson Building, School of Life Sciences, College of Medical, Veterinary and Life Sciences, University of Glasgow, Glasgow, G12 8QQ, United Kingdom

*E-mail: paul.rea@glasgow.ac.uk
\end{abstract}

\begin{abstract}
Introduction: There is little literature on the subvalvular apparatus of the atrioventricular valves' of the heart. This investigation aimed to compare mammalian atrioventricular valve subvalvular apparatus; in particular the number and characteristics of true chordae tendineae (TChT) and their tissue transition areas - proximally with the valve leaflets, and distally with the papillary muscles. Materials and Methods: Sheep, pig and bovine fresh hearts were dissected $(n=9)$. The subvalvular apparatus of the mitral and tricuspid valves were visualised. Each TChT origin was grouped and counted according to papillary muscle and valve, and compared within and across the species. Appropriate statistical analyses were then applied to identify any correlations. Histological examination of the transition areas was also performed. Results: The tricuspid valve had significantly more TChT than the mitral $(p=0.04)$. On comparison of the TChT counts in both valves across the species, there were no significant differences. An unexpected finding was the abrupt transition from chordae collagen to papillary muscle. Conclusion: The tricuspid valve is under less pressure than the mitral but is connected to significantly more TChT. We have shown no significant difference between the numbers of TChT for each papillary muscle in either mitral or tricupsid valves across the species. Veterinary teaching emphasises that there is no clinically significant difference at a gross morphology level between these species. This is the first study to report that there is also no significant difference at the subvalvular level, and this has direct translational relevance for bioprosthetic cardiac valve replacement.
\end{abstract}

Keywords: sub-valvular apparatus, true chordae tendineae, papillary muscles, valve replacements.

\section{Introduction}

Anatomy of the mammalian heart is similar, if not identical, to humans (COLVILLE and BASSERT, 2009). Indeed, in veterinary studies, the model of circulation established in humans is taught as applied to animals, as there are no clinically significant differences. Interestingly, anatomy is taught in many schools using animal models, as the specimens are easier to access than human cadaveric tissue, and closely represent human anatomy (NEW..., 2014). However, what has not been clearly established is if similarities, or indeed differences, occur at the sub-valvular apparatus level.

In humans, valvular heart surgery has been undertaken using either biological or mechanical valves. Biological replacements can come from human cadaveric material or from porcine, bovine or equine species due to the broadly similar anatomical structure. Mechanical valves however require lifelong anticoagulation. Bioprosthetic valves tend to be used for patient's who have a lower life expectancy, especially if other illnesses exist which may necessitate further surgery (HERZOG and COLLINS, 2002). Mechanical valves tend to be used for patient's with accelerated valvular disease, less than 60-65 years old for aortic or mitral valve replacement and for patient's with a reasonable life expectancy (VAHANIAN, ALFIERI, ANDREOTTI et al., 2012). As animal valves have been used, it would suggest an identical anatomical structure in relation to the valves and sub-valvular apparatus. However, we have not been able to identify within the literature any comparative studies comparing the sub-valvular apparatus of the mammalian heart.

The atrio-ventricular (AV) valves differ from the semi-lunar valves (pulmonary and aortic) due to the presence of sub-valvular apparatus. Each valve leaflet is interconnected with string-like chordae tendineae which anchor the leaflets to prevent the valves inverting into the atria under pressure. This anchoring system is even more effective due to the continuous collagen sheet running from the ring-like annulus into the valve cusps and through the chordae tendineae (FENOGLIO JUNIOR, PHAM, WIT et al., 1972).

The composition of chordae tendineae is well suited to the repetitive strain that they undergo during the cyclic motion of systole and diastole. Although they appear as thin tendinous cords, they are remarkably strong. Chordae tendineae are composed of avascular connective tissue with an outer sheath of elastic fibres and a dense collagen core allowing for a high level of durability; they are covered by endocardium (MILLINGTON-SANDERS et al., 1998). There are two subsets of chordae tendineae - false and true. False chordae tendineae (FChT) arise and insert onto the ventricular walls and the majority of them are found inferior to the base of the papillary muscles (KOSINKSI, GRZYBIAK, DUBANIEWICZ et al., 2012). However FChT do not 
connect with the AV valves. True chordae tendineae (TChT) originate from the apical portions of the papillary muscles and insert onto the valve leaflets (LAM, RANGANATHAN, WIGLE et al., 1970). There is wide variation in TChT morphology, specifically between the mitral and tricuspid valves.

As there are no detailed comparative anatomical studies of mammalian heart tissue at the sub-valvular level, this study aimed to provide evidence for this. We set out to investigate the true chordae tendineae (TChT) of mammalian atrioventricular (AV) valves across a range of species, focusing on the sub-valvular apparatus. This study also aimed to investigate the tissue composition of the proximal and distal junctions of the TChT, and to characterise the transition zone. This study used wet dissections of sheep (Ovis aries), pig (Sus domesticus) and bovine (Bos primigenius) hearts. The second part of this study comprised of histological examination at the sub-valvular apparatus level. The purpose of this aspect of the study was to enhance our understanding about the organisation, number and structure of chordae tendineae of the heart in different mammalian species. In view of their clinical importance in the function of the atrioventricular valves, and lack of detailed comparative studies in this area, we aim to clarify these points.

\section{Materials and Methods}

Initial dissection work took place in the post-mortem suites at the University of Glasgow's School Of Veterinary Medicine. In total nine mammalian hearts were dissected; four sheep, three bovine and two pig hearts. All were collected from the Wishaw Abattoir (Glasgow, UK) on the day of kill, and were dissected within one week. The hearts received were cut from the great vessels and pericardium, but had no prior incisions to the main body of the heart, which meant the chambers and AV valves were fully intact. All specimens were kept fresh in sealed containers within a chilled cabinet; no chemical fixatives were injected.

Using dissecting scissors, an incision was made on the lateral side of the heart in order to fully display the mitral valve and minimise damage to the subvalvular apparatus (LAM, RANGANATHAN, WIGLE et al., 1970). A second incision was made on the medial side. Both incisions began at the entrance to the atria and descended inferiorly through the $\mathrm{AV}$ valves to the apices of the ventricles. The right ventricle was found to be larger than the left, and required a further (third) incision that ascended superiorly and posteriorly from the ventricular apex to fully display the tricuspid valve.

There was a pronounced moderator band in both ventricles that attached from the ventricle wall to the interventricular septum. This was cut in order to fully visualise the AV valves. The function of the moderator band is to limit excess distension of the ventricles, and therefore it plays no direct role in AV valve mechanics.

In this investigation only true chordae tendineae (TChT) were counted and studied. From the literature there are many ways of classifying TChT; however they are specific to insertion zones which were not clearly described by Lam, Ranganathan, Wigle et al. (1970). To overcome this and to accommodate the different species, we used a simple classification method that could be applied to all the heart specimens.

An individual TChT was classified as a single point of origin that directly interacted with the apical surface of the papillary muscle and continued superiorly to interconnect with the valve leaflet. False chordae tendineae that did not interconnect with the AV valve leaflets were not counted. The TChT were individually counted and recorded for each papillary muscle in both the mitral and tricuspid valves in all heart specimens.

\subsection{Histology}

Histology specimens were taken from each species and studies focused primarily on the transition areas. A ribbon of tissue was cut beginning at the valve cusp and ending at the papillary muscle. This included the first tissue transition between the valve cusp and the chordae tendineae insertion site and the second transition between the chordae tendineae and the papillary muscle. Samples were taken from the tricuspid and mitral valves of each species; both included chordae tendineae that originated from the anterior papillary muscle. Each ribbon was further dissected to give two sections - one with the first tissue transition and the other with the second tissue transition. Four histology specimens were taken from each species, resulting in 12 histological specimens in total.

Each section was fixed in an individual CellStor Pot (CellPath, Newtown, Powys, UK) and pinned to cardboard to retain its length; each sample was then fixed for four days. Once cut by a microtome and mounted onto a slide, the tissue sections were stained for histological study. Haematoxylin and Eosin (H\&E), and Haematoxylin and Van Gieson stains were used on each block. H\&E stained nuclei purple and connective tissue varying shades of pink. Haematoxylin and Van Gieson stained muscle yellow and collagen bright pink/red. Once stained, the slides were photographed under a light microscope to document the tissue composition of the two different junctions.

TChT counts were grouped into subsets according to the papillary muscle they originated from, and papillary muscle counts were grouped into total TChT valve counts. Comparisons were made between papillary muscle counts across the species, and between mitral and tricuspid chordae counts across the species. Counts were taken on two separate occasions and combined to give consistency.

\subsection{Statistics}

Appropriate statistical analyses were applied to the data to establish if the differences were significant. Comparing the two papillary muscle counts for the mitral valve across the species involved two groups; therefore a Student's T test was used to calculate the $\mathrm{p}$ value. When comparing the three groups of counts from the papillary muscles associate with the tricuspid valve, an ANOVA single factor test was used to calculate the $\mathrm{p}$ value.

\section{Results}

\subsection{Gross dissection}

Figure 1 shows the sub-valvular apparatus of the mitral valve in bovine, pig and sheep hearts. At a gross anatomical level, it would appear that the surface morphology of the apical surface is consistent across the given species. The valve leaflets and the TChT are both composed of collagen, and therefore at this transition point there was no distinguishable change in the tissue. TChT counts for the papillary muscles of the tricuspid valve across the species are shown in Figure 1.

From Figure 2, Graph 1 highlights that there is a no obvious correlation between the number of TChT between the papillary muscles of the tricuspid valve within the same 

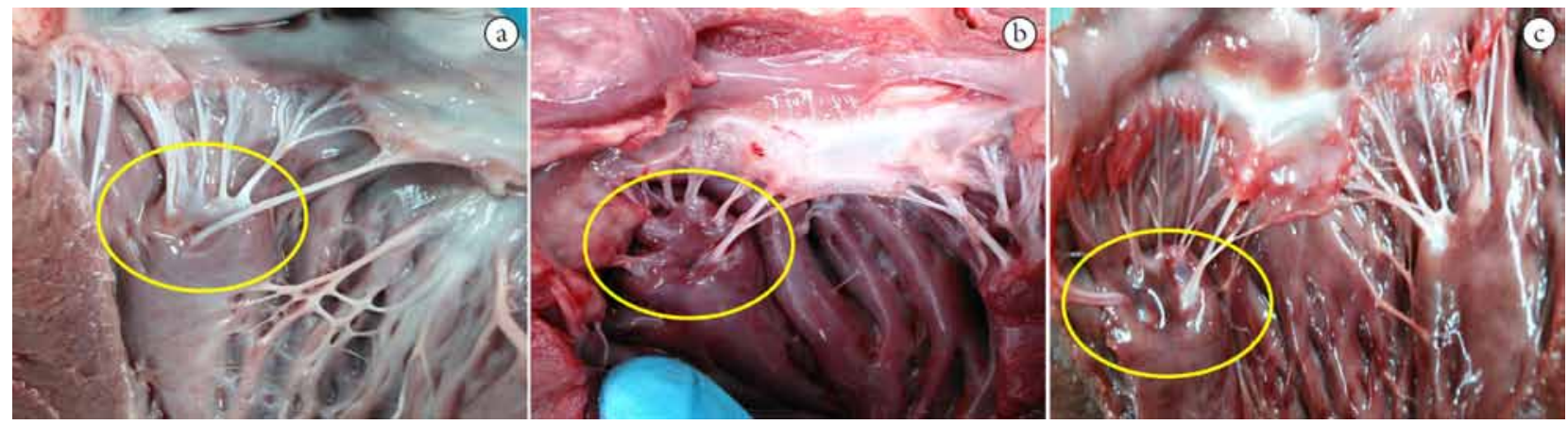

Figure 1. Sub-valvular apparatus of the mitral valve ((a) - Bovine, (b) - Pig, (c) - Sheep)). At the top of each image the valve leaflets of the mitral valve can be seen. Below the cusps are the interconnecting TChT which descend to anchor into the papillary muscles. On the left of each photograph the TChT anchor into the apical portion of the anterior papillary muscle (circled). From observation it can be seen that the surface morphology of the apical surface is similar across the given species.
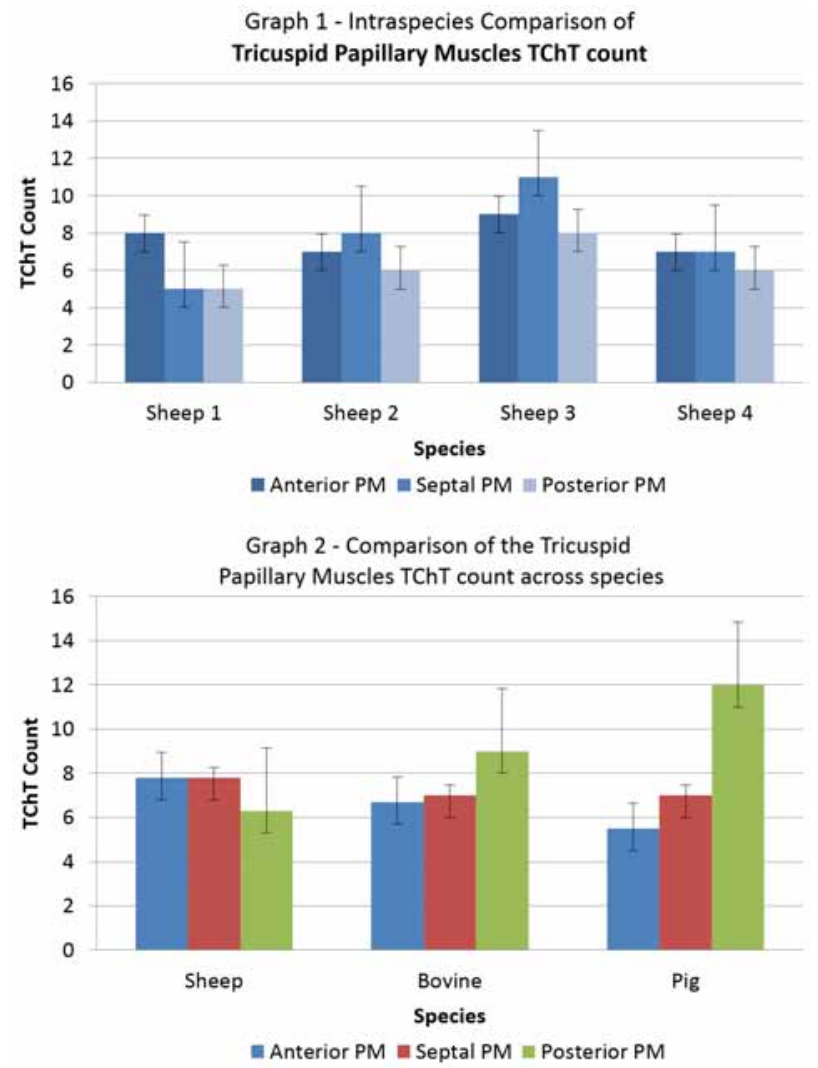

Figure 2. TChT counts for papillary muscles (PM) of the tricuspid valve - intra and interspecies comparisons. The tricuspid valve has three leaflets - anterior, septal and posterior. Both graphs illustrate the comparison of TChT count for each papillary muscle of the tricuspid valve. Graph 1 displays an intraspecies comparison and Graph 2 displays an interspecies comparison.

species $(\mathrm{p}=0.40)$. This was similar across all species. Graph 2 mirrors this relationship between the chordae counts of the tricuspid valve across the given species, with an insignificant $p$ value of 0.30 . This trend was repeated when comparing the TChT counts for the mitral papillary muscles, resulting in a $\mathrm{p}$ value of 0.44 .

Figure 3 clearly demonstrates the significant difference between mitral and tricuspid valve TChT counts $(\mathrm{p}=0.04)$. It is clear that the tricuspid valve has significantly more TChT

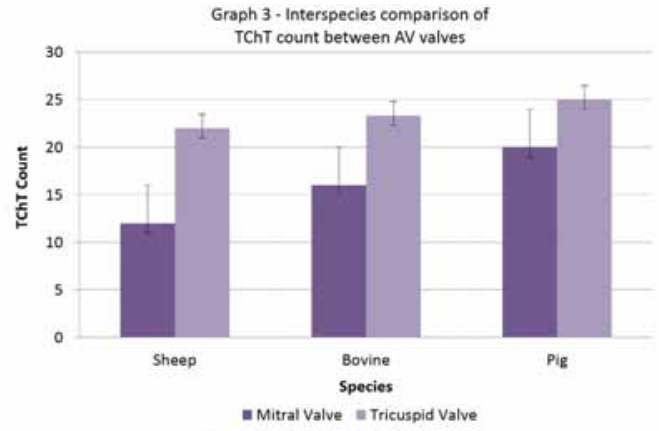

\begin{tabular}{|l|l|l|l|}
\hline Table 1 & \multicolumn{3}{|l|}{ Mean TChT count for AV valves } \\
\hline Species Type & Mitral & Tricuspid & p value \\
\hline Shecp & 12 & 22 & \\
\hline Pig & 16 & 23.3 & \multirow{2}{*}{0.04} \\
\hline Bovine & 20 & 25 & \multicolumn{2}{|l|}{} \\
\cline { 1 - 3 } Mean (Standard Deviation) & $16(4)$ & $23.4(1.5)$ & \\
\cline { 1 - 2 } & & &
\end{tabular}

Figure 3. Comparison of total TChT counts for mitral and tricuspid valves across the given species. There is a significant difference between the counts which is illustrated in Graph 3 and is reinforced by a significant $\mathrm{p}$ value of 0.04 in Table 1 .

than the mitral valve, irrespective of the species, although the proportions vary.

\subsection{Histological analysis}

From Figure 4 an interspecies comparison can be made between the given species' chordae anchorage. Due to the differences in scaling there can be no quantitative comparison of TChT collagen core density. However the characteristics of the junction between the collagen of the chordae and the muscle fibres of the papillary muscles can be determined. These observations showed that the transition from one tissue type to the other is relatively abrupt.

From Figure 5 an intra-species comparison can be made with pig sub-valvular apparatus from the left and right sides of the heart. From the histological slides the bright pink collagen core of the mitral chordae is denser than that from the tricuspid valve.

\section{Discussion}

The relevance of similar sub-valvular morphology across these species is important in veterinary anatomical teaching. At the University of Glasgow's School of Veterinary Medicine, 


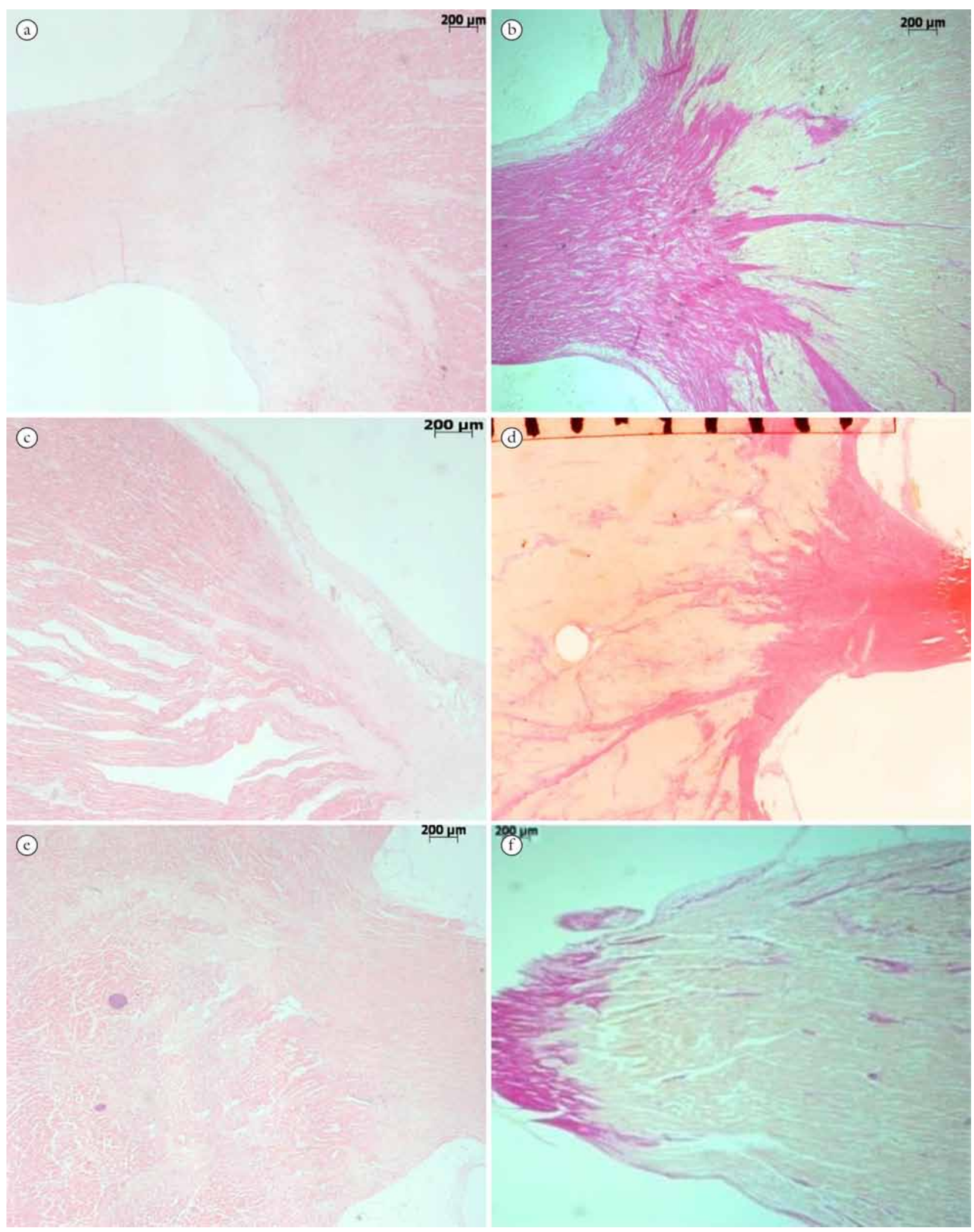

Figure 4. Histological sections from the transition zone of a TChT anchoring into an anterior papillary muscle of the mitral valve. (a) \& (b) - Pig. (c) \& (d) - Bovine. (e) \& (f) - Sheep. (a), (c) and (e) (H\&E stain): junction noticeable but not distinct. (b), (d) and (f) (Haematoxylin and Van Gieson stain): - papillary muscle stained yellow and the collagen core of the TChT is stained bright pink. To fully view the tissue transition in the bovine chordae (d) a larger magnification was used. Each bar represents one millimetre on this section. 


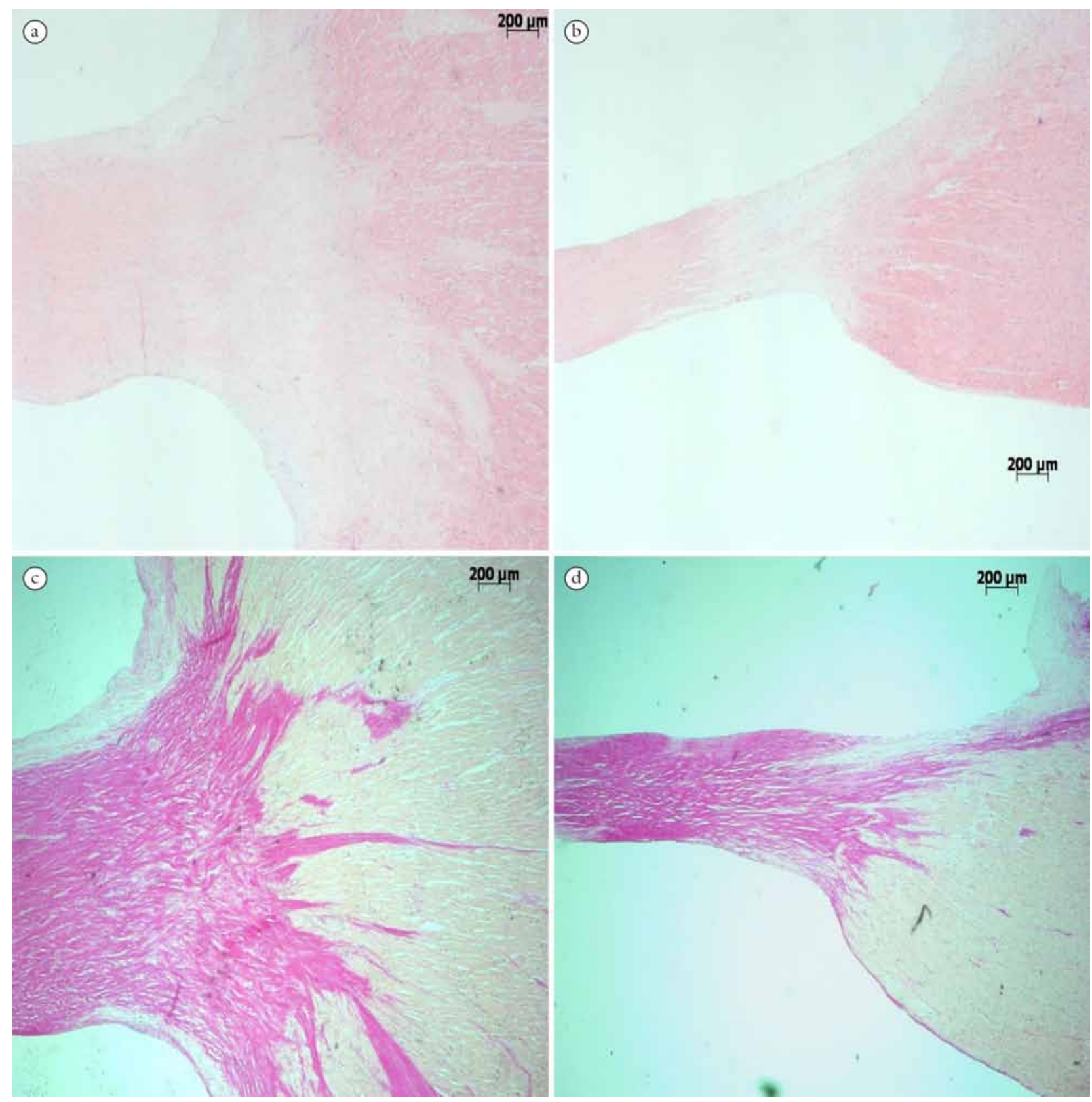

Figure 5. Histological sections of chordae tendineae from a pig's heart. This figure displays samples dissected and stained from the same pig heart, (a), (b), (c) and (d) all show a mid-section from a TChT inserting into an anterior papillary muscle. a and c are taken from the mitral valve, $b$ and $d$ from the tricuspid valve. $a$ and $b$ are stained with H\&E and illustrate the transition from the TChT's collagenous core to the muscle of the PM. $\mathrm{c}$ and d are stained with Haematoxylin and Van Gieson which discretely demonstrates the junction between the pink stained collagen and yellow stained muscle.

the students are taught that at a gross morphological level pig, sheep and bovine hearts have no clinically significant difference between them. This project has demonstrated that there were also no significant interspecies differences at the subvalvular apparatus level. In terms of comparative anatomy and its relevance to human cardiac structure and function, it was important to study the sub-valvular apparatus in view of the use of bioprosthetic (xenograft) valves for surgical transplantation. The dissection work allowed for the full visualisation of the subvalvular apparatus and a direct comparison of the mitral and tricuspid TChT. It is clear that the tricuspid valve has significantly more TChT than the mitral valve. This might be expected as the tricuspid valve is composed of more valve leaflets than the mitral valve. However it could equally have been possible that the increased pressure placed on the mitral chordae on the left side of the heart would have required an increased number of TChT in order to evenly distribute and dissipate the tensile forces placed on them.

The secondary aim of this study was to examine the character of the transition areas of the chordae tendineae. There is little in the literature published on these crucial areas. The tissue transition appeared relatively abrupt on direct observation, which was surprising as the relatively thin string-like chordae are placed under a tremendous and repetitive strain. This is 
surprising as the chordae are placed under a great amount of tension, and therefore further penetration of collagen fibres into the papillary muscle would improve their anchorage. In the literature the reasoning given for this is the presence of microfibrils in the muscle fibres of the basal lamina of the papillary muscle which securely anchor the collagen fibres (FENOGLIO JUNIOR, PHAM, WIT et al., 1972). Future research to fully analyse this tissue transition would require quantitative measurements to examine the exact depth of penetration of the collagen fibres into the papillary muscle. Again there were no obvious interspecies differences in the transition areas.

From the histological studies a number of conclusions could be drawn. From Figure 4 it could be presumed that ventricular pressure has an effect on the cellular blueprint of chordae tendineae. High left ventricular systolic pressure is translated as an increase in the tensile force placed on the mitral TChT which appears to cause a denser central collagenous core; from the histological studies here, the mitral TChT appeared thicker than the tricuspid TChT. In addition, the mitral chordae are under three times more pressure than the tricuspid chordae; therefore a stronger central dense collagenous core would be able to withstand the higher ventricular systolic pressure. A recent study by Mestres and Bernal (2012) gives another possible reason for the increase in collagen. They state that there is a significant increase in collagen synthesis and proliferation of fibroblasts to allow the TChT to resist tension, therefore an increase in tensile forces placed on the chordae will result in an increase in collagen synthesis.

This study has direct clinical and translational relevance to valvular heart surgery, as there is a common trend throughout the literature comparing artificial materials and animal tissue derived options (bioprosthetic or xenograft) for cardiac valve replacement. There is extensive research investigating the advantages and disadvantages of mechanical and bioprosthetic valves, with the major deciding factor being the longevity of the replacement. The current consensus is that younger patients receive a mechanical valve replacement due to its longer durability of 20-30 years. The main disadvantage is the increased risk of thrombosis and, therefore, they require life-long anticoagulation therapy. Patients older than 60 to 65 years are generally given a bioprosthetic valve to avoid complications with anticoagulants. Anticoagulants significantly increase the risk of haemorrhage, and it has been estimated that an elderly patient would have a lifetime risk of bleeding of $41 \%$ compared with a $12 \%$ risk with a bioprosthetic valve (TILLQUIST and MADDOX, 2011). Bioprosthetic valves are commonly porcine or bovine tissue valves (PIBAROT and DUMESNIL, 2009). They are much less durable than the mechanical option due to structural valve deterioration (KULIK, MASTERS, BEDARD et al., 2010) which in turn results in a higher lifetime risk for reoperation of $25 \%$ compared to a reported rate of $3 \%$ for a mechanical valve (PUVIMANASINGHE, STEYERBERG, TAKKENBERG et al., 2001). The current use of animal tissue in life-saving surgery provides evidence to support the continued research into mammalian heart morphology in order to provide a deeper understanding of their subvalvular apparatus.

The discussion regarding artificial and native tissue options is mirrored in the literature concerning the use of chordae tendineae during mitral valve replacement (MVR) surgery. Currently the preferred interventional method uses artificial neochordae tendineae, particularly expanded polytetrafluoroethylene (ePTFE) sutures as they are inert, resist calcification and can be used as a long term option (RIM, LAING, MCPHERSON et al., 2014).

However a recent study by Padala, Cardinau, Gyoneva et al. (2013) investigated whether there was an advantage using either native chordae tendineae or expanded artificial ePTFE neochordae to reconstruct the posterior leaflet during MVR. The study concluded that in an experimental pulsatile model, both gave similar benefits. This suggests that there are no significant advantages between artificial chordae tendineae and native chordae tendineae. Therefore as the use of native chordae is a valid surgical method, further research into human chordae tendineae morphology is required in order to provide the most individually specific option for the patient. From the histological evidence presented here, it can be seen that there are clear differences in chordae tendineae morphology. More detailed investigations are required to refine the classifications used for chordae tendineae.

If the chordae tendineae are to be preserved during surgery, there is also current controversy in the clinical literature regarding which method is the most successful, and there is no single standard surgical technique for preserving native chordae tendineae during mitral valve replacement (MVR). Studies and surgeons argue over the advantages of complete and partial preservation of the chordae tendineae during MVR. Partial preservation (PP) only maintains the chordae tendineae from the posterior leaflet and excise the chordae tendineae that were connected with the anterior leaflet. Complete preservation (CP) maintains the chordae tendineae from both the anterior and posterior leaflets.

$\mathrm{CP}$ allows more native tissue to interact with the prosthesis therefore improving the natural synchronisation of the heart and the replacement valve. A study by Yun, Sintek, Miller et al. (1999) cited significantly improved results with $\mathrm{CP}$ as it reduces the left ventricle chamber size and therefore end systolic volume, resulting in lower pressure on the heart. In contrast some surgeons argue that complete preservation of the chordae tendineae will disrupt blood flow, may interact with the prosthesis and extends operating time (SINTEK, PFEFFER, KOCHAMBA et al., 1995). A recent meta-analysis by Sá, Escobar, Ferraz et al. (2013) stated that there was no significant difference in outcomes between partial and complete preservation. This provides a valid argument that more research is required to understand mammalian chordae tendineae morphology and arrangement, and research trials may require a mammalian heart experimental model similar to a human.

An aspect from this investigation that had noticeable potential for further research was classifying the type of chordae insertion sites. During the dissection work it was clear from observation that there was a difference between the mitral and tricuspid chordae insertion sites, particularly onto the valve leaflets. Maisano, Lorusso, Sandrelli et al. (1996) noticed that, where the tricuspid chordae insert onto the free edge of the valve leaflets, there was a distinct rim of bunched red tissue, which was classified as "small branches." This was also observed in this study's dissection work and was in stark contrast to the clearly defined insertions of the mitral chordae. Moreover it was clear that the chordae of the mitral valve were more opaque and well defined than the translucent tricuspid chordae. Maisano, Lorusso, Sandrelli et al. (1996) had also 
noted this saying "there was a flimsy nature to the tricuspid leaflets and subvalvular apparatus."

\section{Conclusion}

To our knowledge, this is the first study to report on the comparative anatomy of the sub-valvular apparatus of the heart in sheep, cow and pig, all of which are candidate species used for bioprosthetic valve replacement surgery. It is also the first study to start to examine the transition areas of the chordae tendineae. Several promising areas for future translational research have been identified.

Acknowledgements: We are extremely grateful to many colleagues who have given their time and expertise to this project. University of Glasgow's Laboratory of Human Anatomy: Mr Andrew Lockhart - Senior Laboratory Technician, Mr David Russell - Histology Laboratory Technician. University of Glasgow's School of Veterinary Medicine: Mr Richard Irvine - Head Technician at the post-mortem suites, Mrs Lynn Stevenson - Senior Histopathology Technician.

\section{References}

COLVILLE, TP. and BASSERT, JM. Clinical anatomy and physiology laboratory manual for veterinary clinicians. St Louis: Elsevier. 2009. $234 \mathrm{p}$.

FENOGLIO JUNIOR, JJ., PHAM, TD., WIT, AL., BASSETT, AL. and WAGNER, BM. Canine Mitral Complex: ultrastructure and electromechanical properties. Circulation Research, 1972, vol. 31, n. 3, p. 417-430. http://dx.doi.org/10.1161/01.RES.31.3.417. PMid:5057021.

HERZOG, CA., MA, JZ. and COLLINS, AJ. Long-term survival of dialysis patients in the United States with prosthetic heart valves: should ACC/AHA practice guidelines on valve selection be modified? Circulation, 2002, vol. 105, n. 11, p. 1336-1341. http://dx.doi. org/10.1161/hcl102.100075. PMid:11901045.

KOSINKSI, A., GRZYBIAK, M., DUBANIEWICZ, A., KEDZIORA, K., MAKAREWICZ, W., and KOZLOWSKI, D. False chordae tendineae in right ventricle of adult human hearts: morphological aspects. Archives of Medical Science, 2012, vol. 8, n. 5, p. 834-840. http://dx.doi.org/10.5114/aoms.2012.31617.

KULIK, A., MASTERS, RG., BEDARD, P., HENDRY, PJ., LAM, BK., RUBENS, FD., and RUEL, M. Postoperative lipid-lowering therapy and bioprosthesis structural valve deterioration: justification for a randomised trial? European Journal of Cardio-Thoracic Surgery, 2010, vol. 37, n. 1, p. 139-144. http://dx.doi.org/10.1016/j. ejcts.2009.06.051.

LAM, JHC., RANGANATHAN, N., WIGLE, ED. and SILVER, MD. Morphology of the human mitral valve: I. Chordae tendineae: a new classification. Circulation, 1970, vol. 41, n. 3, p. 449-458. http:// dx.doi.org/10.1161/01.CIR.41.3.449. PMid:5415982.

MAISANO, F., LORUSSO, R., SANDRELLI, L., TORRACCA, L., COLETTI, G., LACANNA, G. and ALFIERI, O. Valve repair for traumatic tricuspid regurgitation. European Journal of CardioThoracic Surgery, 1996, vol. 10, n. 10, p. 867-873. http://dx.doi. org/10.1016/S1010-7940(96)80313-7. PMid:8911840.

MESTRES, C-A. and BERNAL, JM. Mitral valve repair: the chordae tendineae. The Journal of Tehran Heart Center, 2012, vol. 7, n. 3, p. 92-99. PMid:23304176.

MILLINGTON-SANDERS, C., MEIR, A., LAWRENCE, L. and STOLINSKI, C. Structure of chordae tendineae in the left ventricle of the human heart. Journal of Anatomy, 1998, vol. 192, Pt 4, p. 573-581. http://dx.doi.org/10.1046/j.1469-7580.1998.19240573.x.

NEW ENGLAND ANTI-VIVISECTION SOCIETY - NEAVS. NEAVS $^{\mathrm{TM}}$. Boston, 2014. Available from: <http://www.neavs.org>. Access in: 29 May 2014.

PADALA, M., CARDINAU, B., GYONEVA, LI., THOURANI, VH. and YOGANATHAN, AP. Comparison of artificial neochordae and native chordal transfer in the repair of a flail posterior mitral leaflet: an experimental study. The Annals of Thoracic Surgery, 2013, vol. 95, n. 2, p. 629-633. http://dx.doi.org/10.1016/j.athoracsur.2012.09.055. PMid:23291143.

PIBAROT, P. and DUMESNIL, JG. Prosthetic heart valves: selection of the optimal prosthesis and long-term management. Circulation, 2009, vol. 119, n. 7, p. 1034-1048. http://dx.doi.org/10.1161/ CIRCULATIONAHA.108.778886. PMid:19237674.

PUVIMANASINGHE, JPA., STEYERBERG, EW., TAKKENBERG, JJM., EIJKEMANS, MJC., VAN HERWERDEN, LA., BOGERS, AJJC. and HABBEMA, JDF. Prognosis after aortic valve replacement with a bioprosthesis: predictions based on meta-analysis and microsimulation. Circulation, 2001, vol. 103, n. 11, p. 1535-1541. http://dx.doi. org/10.1161/01.CIR.103.11.1535. PMid:11257081.

RIM, Y., LAING, ST., MCPHERSON, DD. and KIM, H. Mitral valve repair using ePTFE sutures for ruptured mitral Chordae tendineae: a computational simulation study. Annals of Biomedical Engineering, 2014, vol. 42, n. 1, p. 139-148. http://dx.doi.org/10.1007/s10439013-0908-1. PMid:24072489.

SA, MPBDO., ESCOBAR, RR., FERRAZ, PE., VASCONCELOS, FP., and LIMA, RC. Complete versus partial preservation of mitral valve apparatus during mitral valve replacement: meta-analysis and meta-regression of 1535 patients. European Journal of Cardio-thoracic Surgery, 2013, vol. 44, n. 5, p. 905-912. http://dx.doi.org/10.1093/ ejcts/ezt059.

SINTEK, CF., PFEFFER, TA., KOCHAMBA, GS. and KHONSARI, S. Mitral valve replacement: technique to preserve the subvalvular apparatus. The Annals of Thoracic Surgery, 1995, vol. 59, n. 4, p. 1027-1029. http://dx.doi.org/10.1016/0003-4975(95)00030-O. PMid:7695385.

TILLQUIST, MN. and MADDOX, TM. Cardiac crossroads: deciding between mechanical or bioprosthetic heart valve replacement. Patient Preference and Adherence, 2011, vol. 5, p. 91-99. http://dx.doi. org/10.2147/PPA.S16420. PMid:21448466.

VAHANIAN, A., ALFIERI, O., ANDREOTTI, F., ANTUNES, MJ., BARÓN-ESQUIVIAS, G., BAUMGARTNER, H., BORGER, MA., CARREL, TP., BONIS, T., EVANGELISTA, A., FALK, V., IUNG, B., LANCELLOTTI, P., PIERARD, L., PRICE, S., SCHÄFERS, H.-J., SCHULER, G., STEPINSKA, J., SWEDBERG, K., TAKKENBERG, J., VON OPPELL, UO., WINDECKER, S., ZAMORANO, JL. and ZEMBALA, M. Guidelines on the management of valvular heart disease (version 2012). European Heart Journal, 2012, vol. 33, p. 2451-2496. ESC/EACTS Guidelines. Available from: <http:// eurheartj.oxfordjournals.org/content/33/19/2451.full.pdf+html>. Access in: 29 May 2014.

YUN, KL., SINTEK, CF., MILLER, DC., SCHUYLER, GT., FLETCHER, AD., PFEFFER, TA., KOCHAMBA, GS., KHONSARI, S. and ZILE, MR. Randomized trial of partial versus complete chordal preservation methods of mitral valve replacement: a preliminary report. Circulation, 1999, vol. 100, supplement 19, p. II90-II94. http:// dx.doi.org/10.1161/01.CIR.100.suppl_2.1190. PMid:10567284.

Received May 4, 2014 Accepted September 1, 2015 